\title{
Nurses' Role and Experiences as Group-Leaders in a Group Intervention for Women after Gynecological Cancer
}

\author{
Ragnhild Johanne Tveit Sekse, Margrethe Elin Vika \\ Haukeland University Hospital, Bergen, Norway \\ Email: ragnhild.johanne.sekse@helse-bergen.no, Margrethe.Elin.Vika@hfk.no
}

Received 9 February 2016; accepted 20 March 2016; published 24 March 2016

Copyright (C) 2016 by authors and Scientific Research Publishing Inc.

This work is licensed under the Creative Commons Attribution International License (CC BY). http://creativecommons.org/licenses/by/4.0/

\section{(c) (i) Open Access}

\begin{abstract}
Aim: The aim of this study is to provide insight into nurses' role and their experiences of leading an education and counselling group intervention for women after gynecological cancer. Methods: A qualitative study, based on focus group interview and logs from nurses who led the intervention, was conducted. Findings: The group leaders were touched by the women's community and were given a deeper understanding of lived experiences after cancer. These insights raised the groupleaders' understanding of nursing and influenced them to sharpen focus on patient care and priorities in cancer care and follow-up. Being a group-leader meant creating a trusting and secure atmosphere in which the individual woman's own coping resources was strengthened and empowered. Equally important, the nurses worked continuously and substantially on themselves to build strength and endurance related to situations that called for competent leadership. Conclusion: Being competent in group leadership and having knowledge in the field of cancer are important qualifications for group leaders. Practice Implications: The study shows that nurses gain valuable insight and knowledge about women's lived experiences of going through gynecological cancer, cancer treatment and rehabilitation. As such, this intervention seems to be educational for nurses, as well as for participants.
\end{abstract}

\section{Keywords}

Gynecological Cancer, Nurses' Experiences, Nurse-Led Intervention, Rehabilitation

\section{Introduction}

People who have a history of cancer express the need for a more holistic approach concerning their treatment

How to cite this paper: Sekse, R.J.T. and Vika, M.E. (2016) Nurses' Role and Experiences as Group-Leaders in a Group Intervention for Women after Gynecological Cancer. Open Journal of Nursing, 6, 239-247.

http://dx.doi.org/10.4236/ojn.2016.63024 
trajectory and rehabilitation process [1]-[5]. In a review of women who survived gynecological cancers [6], Chase et al. conclude that psycho-social issues were poorly taken care of. Rutten et al. [7] underscore in yet another review the need for more knowledge throughout cancer trajectories and particularly related to rehabilitation processes. At the same time, cancer care faces demands of becoming more effective and extensive. Altogether this puts pressure on the time used with each patient and thus may result in less supportive conversations, information and guidance. Alternative approaches to follow-up, such as various rehabilitation services and nurse-led services, have been offered to counter such consequences.

Various interventions concerning rehabilitation services have shown positive results in cancer care [8]-[14], including gynecological cancer care [15]. Hersch et al. [15] concluded in their review, that counselling appears as the most promising intervention strategy for addressing health-related QoL-concerns for women who have had gynecological cancer.

Nurses often have a key role as providers of information and guidance to cancer patients. Cox et al. [16] evaluated in a review the impact of follow-up in cancer care that was led by nurses. They concluded that nurse-led follow-up was both appropriate and effective and could be an efficient way of maintaining support to patients who are vulnerable during their transition to aftercare and daily life beyond. Another systematic review echoes these findings [17]. The Cochrane review by Galaway et al. [18] concluded that nurse-delivered interventions comprising information combined with supportive attention may have beneficial impact on mood in an undifferentiated population of newly diagnosed cancer patients. In a meta-analyses Zabalegui et al. [10] conclude that nurses should promote participation in support groups as a crucial part of cancer care, and that future nursing education should include knowledge and skills necessary to carry such interventions. However, few studies have explored extensively the nurses' roles and experiences of being group-leaders for cancer patients in support groups. In a previous study [19] we focused on participants' experiences of attending an education and counselling group intervention. The findings led us on to ask how the nurses themselves describe in-depth their role as group-leaders. The aim of the present article is to explore the nurses' roles and experiences of leading an education and counselling group intervention for women after gynecological cancer.

\section{Methods}

The present study, focusing on nurses’ role and experiences as group-leaders in an education and counselling group programme is part of a larger study. The purpose of the latter was to measure and compare the effects of two interventions on women's self-reported quality of life and coping, namely an education and counselling group versus a physical training group.

\subsection{The Nurse-Led Intervention and Theoretical Approach}

The education and counselling group intervention consisted of two nurses, from three different hospitals, who facilitated the group of women treated for gynecological cancer. The group sessions took place once a week (2.5 hours) over a period of seven weeks. The nurses led the sessions, consisted of a part of lecture on a relevant topic, and a counselling session focusing on the women's needs and experiences. The seven standardized topics were: Bodily changes, coping and coping strategies, fatigue and nutrition, social rights, getting back to work, sexuality, and life beyond cancer. The participants in the intervention groups were women living in three different cities in Norway. The main inclusion criteria for participating in the intervention were: Having completed treatment for gynaecological cancer within the last two years and being free from recidive.

To ensure that the intervention was standardized, a protocol with detailed content was made. Description of the content, the schedule of each session, and a presentation of the various themes for each session, were written down. A one-day seminar was arranged to calibrate the nurses according to a written protocol. They worked through the program according to the protocol and were given the possibility to test the group-leader role. The first and last authors were responsible for the preparation of the intervention in collaboration with a multidisciplinary team, consisting of researchers and clinicians.

The theoretical basis for the intervention was Antonovsky’s salutogenetic theory [20] [21] and Roger's clientcentred therapy [22] [23]. As such, the nurses' function was more being a dialogue partner, balancing between listening to the women's everyday lives and challenges, as well as their strengths and resources. By asking questions and being increasingly aware of the individual woman's own resources, the focus may lead to increased coping skills. Furthermore, if several of the women had similar experiences, it was more important to expose their variations, rather than to solve the problems. The idea was that the individual woman could take into con- 
sideration what was useful for herself [24].

Before each group sessions, it was important that the group-leaders had enough time ahead of each group session, to tune themselves mentally. This included being in the group room well in advance of the group members arrival. The focus was to be present here and now, and to be genuinely interested in and focused on the individual woman and her story [23]. The group-leaders knew every single woman by name and all were greeted personally when they arrived at the group session.

The two group-leaders had eye contact and sat diagonally opposed to each other during the session. After each group session, the group group-leaders had time for recap and reflection. They were encouraged to talk about and write down their experiences and reflections.

\subsection{Focus Group, Participants and Data Collection}

A focus group interview and logs were chosen to illuminate and deepen the knowledge about nurses' roles and their experiences of being group-leaders in an intervention. These methods are useful for acquiring a broader knowledge and understanding of the topic discussed [25].

The inclusion criteria for the nurses as group-leaders were competence in counselling and experience with gynecological cancer care. The group leaders also had to be working at a gynecological cancer unit. All the six group-leaders, two from each of three hospitals in Norway, were asked to participate in a focus group when they had completed one series of group intervention sessions. In addition, the group leader logs from these intervention's seven sessions were collected. The nurses were all women, between 38 and 58 years old (average age 49). They had all worked many years as registered nurses (average 24 years), as well as in the gynecological unit (from 7 - 18 years, average 10 years). Three out of six nurses had postgraduate degrees in cancer care, whereas four had degrees in counselling. All group-leaders were from the same ethnic group. The study was carried out between 2009 and 2012.

The focus group interview was made in a quiet room with no disturbances and lasted about two hours. All the participants were seated around a table. The moderators prepared an interview-guide that contained broad topics and thus gave direction to the group discussions. However, the nurses were encouraged to talk as freely as possible about their experiences as group-leaders. The interview guide's main theme was the nurses' experiences of leading an education- and counselling group intervention. The opening question was: "Could you tell us about your experiences as group leaders?" Among other questions were "What were the most important functions you had as group leader?" and "What was your greatest challenge in that role?"

All group-leaders were asked to write logs from the groups. They were encouraged to write freely but also answered some questions about two main topics; group-members' processes (from the nurses' perspectives) and group leaders' processes. The logs were collected at the end of the intervention.

The authors conducted the focus group interview and collected logs from the nurses. The first author, a nurse, $\mathrm{PhD}$ and counsellor, was moderator of the group. Her nursing experience was from cancer care. As a researcher she had her main experiences related to qualitative research based on individual interviews and focus group interviews. The last author and co-moderator was a nurse, psychologist and $\mathrm{PhD}$. A reflective attitude was maintained during the entire process [26] [27].

\subsection{Data Analysis}

The analysis was done through Kvale's meaning condensation [27]. The focus group interview was audiorecorded and the first author transcribed the recordings verbatim. The logs were gathered. All the data were read through several times to achieve a general understanding and to search for common themes the nurses as group-leaders were preoccupied with. Repeated readings through all the materials followed, noting important words and topics continually in the text. The clues of meaning were searched for, reflected on those found, and notes taken. Meaningful structures containing quotes and condensed descriptions that illuminated the topics were written down and summarized. Three main topics emerged: Being touched by the women's community; Gaining more knowledge and understanding of nursing; and Caring, learning and endurance in the role of counselling.

\subsection{Ethical Considerations}

The study was approved by the regional Committee for Medical Research Ethics (2009/896) and the Norwegian 
Social Science Data Services. The six nurses who led the intervention groups in all three cities, conceded to participate and to have their logs analysed. The nurses were informed that participation was voluntary and that they could withdraw from the study at any time. The names of the nurses were altered to ensure anonymity.

\section{Findings}

The group-leaders had gained insight and knowledge that led to a deeper understanding of the fellowship of women after gynecological cancer. Being group-leaders had affected them, both through witnessing and participating in the women's community. These insights had broadened their understanding of nursing and influenced them to sharpen their focus on patient care and priorities in cancer care and follow-up. Furthermore, being a group-leader meant creating a trusting and safe atmosphere in which the individual woman's own resources were strengthened and empowered. The nurses also worked continuously and substantially on themselves to build strength and endurance related to situations that called for competent leadership.

\subsection{Being Touched by the Women's Community}

All the group leaders were touched by being witness to and participating in, the fellowship of women. A unique community where understanding and belonging were in the foreground was described. One group-leader said:

"What struck me was the experience of how good it was for the women to meet each other and the immediate feeling of trust that was established between them. They understood each other...did not use many words, but still...they had a need to be together and to share..."

The group leaders reported that women in the fellowship expressed the want of someone to talk to and of being understood for what they had been through. One leader said:

"The women in the group spoke of what it meant to be in a setting where they could share what they had been through... This was not something they could do in everyday life... They were so grateful to have access to the group and the women with similar experiences. That was the essence of it."

The nurses spoke of conversations in the group fellowship which had sharp thematic contrasts spanning from the vulnerable and difficult to casual life, happiness and laughter. This could be a challenge for the group leaders related to caring for the individual, but at the same time they saw that, for the women themselves, this was how life really was. One nurse said:

"One woman in the group was happy for being healthy today, while another was sad for not being able to work again. Still they spoke openly about this and were very supportive to each other."

For the nurses, seeing how the women handled this dichotomy helped them reflect and understand the dimensions of challenges and changes following cancer illness.

\subsection{Increased Understanding and Knowledge of Nursing}

The greatest outcome for the group leaders was related to their understanding of nursing, which had been broadened through their insight into the women's experiences and narratives. As such, consequences for the gynecological unit at the hospital were also expressed.

While talking about how a deeper understanding of nursing was gained, one group-leader said: "There was much learning in listening to the women's stories and experiences... and mostly learning related to my role as a nurse.” Another nurse added:

"The experiences as a nurse, the topics at the sessions, were in themselves the same as those which are important in practice in a hospital. They were the same topics that the women were engaged in and spoke about."

Better insight and understanding of the women's experiences had sharpened the group leaders focus related to priorities at the units. A group-leader said: "You become more observant and know more of what the women need when they arrive at the units and are ill.” The group leaders shared their experiences concerning topics raised by the women, and feedback they received from the participants, with the unit's nurses and other health 
professionals in meetings and learning forums. This gave heightened attention to priorities and patient-focused care.

Several nurses said that many of the women were concerned that their experiences should be returned to the hospital and, if possible, lead to changes in practice. One group leader said:

"Many of the women wanted to bring forth things they had reacted to and we were open and receptive and said we would relay back to the units what they had experienced as poor practice."

Several nurses had experienced that such feedback to the units had been received in a good manner. The women's stories and needs had led to some concrete changes in care planning that had affected patients in a good way, as a nurse said:

“Concrete issues and improvements arose... for example that follow-up visits were poorly conducted....and we would relay this message when we were back at the unit, saying that we just can't act in this way....and we would talk about these issues and how we could benefit from these experiences in the future."

The group leaders had won a deeper understanding of women beyond gynecological cancers, and thereby of nursing.

\subsection{Caring, Learning and Enduring as Group Leaders}

Being a group leader was very satisfying, but also demanding on many levels and within several areas. Creating a trusting and safe atmosphere, seeing each participant and focusing on what could strengthen and empower the women's own coping resources, was essential. Self enhancement, strengthening the ability to endure and stay in difficult and unpleasant situations and enduring silence and unstructured conversations, were among other challenges.

The group leaders were concerned about building an open, safe and trusting atmosphere. Seeing and meeting the individual woman entailed, for the group leaders, contributing to making safe boundaries. One nurse said: "To see everyone...each and every one...to let all contribute...to say whatever they wanted....was very important.” The group leaders experienced that as the women in the groups became more familiar with each other they also shared more with one another. The nurses thought of it as a confirmation of trust when the women opened up little by little and gradually shared their vulnerable stories as they became more confident in each other.

To see and care for everyone, it was necessary to be two group leaders;

"The two of us...we could have eye contact...we agreed on things in advance...and evaluated afterwards... we would talk about how things went, how we handled situations, whether we had forgotten anything, etc... To me this was very necessary.”

All the nurses agreed upon being two leaders, to give feed-back and taking care of all, as one of them said: “...the women are so open....and there are so many vulnerable themes...it is necessary."

All the nurses agreed upon this and one said:

"You need to see everyone, to absorb everything ... that makes it important to have a companion. ... We might hear and comprehend things that are said differently.... or something there I didn’t catch...To have a supportive discussion afterwards was essential.”

Right after each meeting, the group leaders debriefed and gave constructive feedback to each other.

Furthermore, the nurses found it necessary to have competence in counselling and long experience from the clinical, gynecological field. One said:

"To have both education in counselling and knowing the patient group from daily work experience, knowing their unit, and knowing the field, was essential to provide what they needed when they came to the group.”

The nurses described the group-leader role as challenging in different ways. One of the challenges was to find balance in the fellowship, in which all could be seen and have their place. One group-leader said:

“Especially when you sit there the first times and don't know each other so well...you sit and think...when should I get on the court? ... I had this feeling strongly. And how early should I intrude when someone is 
dominating or taking too much room?”

The group leaders felt that working with this balance was a continuous part of the job. Another challenge was to endure silence in the group. One nurse said: "Being able to keep your mouth shut...longer than you usually would think necessary. To practice on this is crucial in such a role.”

Making room for everyone to contribute in a group was important. However, some were more quiet and may wished to be so. A group-leader reflected:

"I was occupied with letting everyone talk, but some have more of a need just to listen... and some of them said this at the last session: 'This (group) has been fantastic!' ... There is much learning in listening...”

The group leaders' experienced that the most quiet members seemed to gain well as much as the more active.

Another challenge was the experience of leading a new group of people which did not cohere with one's expectations or pre-understanding of group leadership. One of the group leaders said she felt that the group discussion was rather rambling along undecidedly, making it difficult to moderate. She worked consciously on enduring this:

"I was used to opening with 'Today we will talk about coping, fatigue'...but then they would all talk at once, jumping from topic to topic, ....and gradually I realized that they really wanted to have it this way.... So I let go and allowed them to speak their hearts. I couldn't be so controlling, but rather more flexible. I believe I struggled with this all the way through...”

Feedback from her co-leader was also crucial for her in order to endure and understanding the group member's needs in this respect.

Further reflections on the various challenges in the group were summarized in this way by one of the nurses:

"I'm sitting there feeling that things should be such and such...but then I feel this is not what happens... However, afterwards I remain with the incredible feeling that all the women expressed an enormous satisfaction, which remains me that I can become too self-critical. As a group leader I focus on everything that could be different, but realize that the group members do not. So, maybe this is the group-leader's problem?”

\section{Discussion}

In this study findings show that the nurses who were group-leaders gained a deeper understanding of participants' lived experiences beyond gynecological cancer. The nurses were touched by both witnessing and participating in the unique community among peers, in which understanding and belonging were in the foreground. This confers with other studies on support groups that emphasize the experience of being understood and accepted as a core value among peers [9] [10] [14] [19] [28] [29]. In our former study related to women's experiences attending the education and counselling group intervention [19], the relationships forged in a support group seemed to be based on a unique understanding of cancer experience, which cannot be fully comprehended by those who have not had cancer. This particular fellowship and unique understanding were given the groupleaders to take part in.

Findings show that being a group-leader meant creating a trusting and safe atmosphere in which the individual woman's own resources were strengthened and empowered. Given Antonovsky's [21] salutogenetic theory and Roger's [22] therapy-centred approach, the nurses' main attention was to the women's own resources. This contributed to empowering the women within holistic care-giving. Zabalegui et al. [10] found in their review and meta-analysis that the nurses' main role was to provide emotional support and promote patients' adaption to their illness through psychological interventions. In our study we question if nurses have improved care giving by using a holistic approach throughout the cancer trajectory and follow-up. In this way the exchange of knowledge and information, combined with the women's lived experience, might be helpful for patients and also educational for health personnel. The nurse-led rehabilitation programme might, as such, improve current practice.

In a study by Gray \& Fitch [30] self-help groups functioned as establishment for better links with health personnel, something also emphasized in a review by Ussher et al. [28]. Even though several studies [28] [31] have shown that there are no differences between professionally led and peer led support groups, other studies clearly emphasize health professionals' impact and participation as group leaders [13] [19]. In our previous study [19], the findings show that participation of skilled and dedicated health personnel who were attentive to assist coping 
and empowerment, was important to the women's outcome. This finding is similar to Morse et al. [13], in which data appears to validate professionally-led psycho-educational cancer support groups, which includes emotional support as well as the provision of education and information.

The findings show that the group leader skills and knowledge related to the cancer form were valued as essential in the nurses' role as group leaders. In a review and meta-analysis concerning nursing and cancer support groups [10], the researchers report that type of leader, and how he/she had managed the group, was one of the most important aspects. The study concludes that nurses need to be qualified in terms of group leadership skills and to be knowledgeable about various issues related to cancer diagnosis, treatment and care that might arise during the group sessions. In our study, the nurses had substantial clinical experience in the field of gynecological cancers and skills in group leadership. Findings from the former study [19] show that the women highlighted these qualities as important. Thus, we agree with Zabalegui et al. [10] when they underscore the need for knowledge of cancer-related issues and group leader skills in order to carry out this type of intervention.

Focus group interviews are highly useful for creating dialogue and exploring common meaning and knowledge. However, in group interviews, participants might lack the courage to reporting negative or interpersonal stress. Furthermore, individual interviews could possibly have explored the phenomena under investigation to a further extent.

Having a reflective and sensitive awareness of our own pre understanding, as well as to the research process and analysis as a whole, was important throughout the study [27] [32]. The researchers worked to establish an open, authentic and dialogue-based relationship with participants and texts.

\section{Limitations and Methodological Considerations}

Focus groups produce data offering potentially powerful insights into a phenomenon. Nevertheless, data collection based on focus group interviews might vary due to differences in group interaction and group dynamics. Individual interviews or several focus groups could possibly have explored the phenomena under investigation further.

\section{Conclusions}

The nurse-led intervention seems to have improved the nurses' care giving by providing a deeper understanding of women's lived experiences after gynecological cancer. This broadened the group leaders' understanding of nursing and influenced them to sharpen their focus on patient care and priorities in cancer care and follow-up. Self-enhancement, through strengthening one's own ability to endure and stay in challenging situations and through enduring silence and unstructured conversations, were other challenges in the field of counselling.

The findings show that being competent in group leadership and having knowledge in the field of cancer are important qualifications for intervention group leaders.If such interventions are to be carried out in the future, such skills need to be included and integrated with nursing education programs.

\section{Practice Implications}

The study shows that nurses gain valuable insight and knowledge about women's lived experiences of going through gynecological cancer, cancer treatment and rehabilitation. As such, this intervention seems to be educational for nurses, as well as for participants.

\section{References}

[1] Carter, J., Stabile, C., Gunn, A. and Sonoda, Y. (2013) The Physical Consequences of Gynecologic Cancer Surgery and Their Impact on Sexual, Emotional, and Quality of Life Issues. The Journal of Sexual Medicine, 10, 21-34. http://dx.doi.org/10.1111/jsm.12002

[2] Krychman, M. and Millheiser, L.S. (2013) Sexual Health Issues in Women with Cancer. The Journal of Sexual Medicine, 10, 5-15. http://dx.doi.org/10.1111/jsm.12034

[3] Papadakos, J., Bussière-Côté, S., Abdelmutti, N., Catton, P., Friedman, A.J., Massey, C., et al. (2012) Informational Needs of Gynecologic Cancer Survivors. Gynecologic Oncology, 124, 452-457. http://dx.doi.org/10.1016/j.ygyno.2011.10.030

[4] McGarry, S., Ward, C., Garrod, R. and Marsden, J. (2013) An Exploratory Study into the Unmet Supportive Needs of 
Breast Cancer Patients. European Journal of Cancer Care, 22, 673-683. http://dx.doi.org/10.1111/ecc.12076

[5] Pascal, J., Johnson, N., Dickson-Swift, V., McGrath, P. and Dangerfield, F. (2015) Understanding Receptivity to Informal Supportive Cancer Care in Regional and Rural Australia: A Heideggerian Analysis. European Journal of Cancer Care, 1-10. http://dx.doi.org/10.1111/ecc.12337

[6] Chase, D.M., Monk, B.J., Wenzel, L.B. and Tewari, K.S. (2008) Supportive Care for Women with Gynecologic Cancers. Expert Review of Anticancer Therapy, 8, 227-241. http://dx.doi.org/10.1586/14737140.8.2.227

[7] Rutten, L.J.F., Arora, N.K., Bakos, A.D., Aziz, N. and Rowland, J. (2005) Information Needs and Sources of Information among Cancer Patients: A Systematic Review of Research (1980-2003). Patient Education and Counseling, 57, 250-61. http://dx.doi.org/10.1016/j.pec.2004.06.006

[8] Rehse, B. and Pukrop, R. (2003) Effects of Psychosocial Interventions on Quality of Life in Adult Cancer Patients: Meta Analysis of 37 Published Controlled Outcome Studies. Patient Education and Counseling, 50, 179-186. http://dx.doi.org/10.1016/S0738-3991(02)00149-0

[9] Gottlieb, B.H., Wachala, E.D. (2007) Cancer Support Groups: A Critical Review of Empirical Studies. PsychoOncology, 16, 379-400. http://dx.doi.org/10.1002/pon.1078

[10] Zabalegui, A., Sanchez, S., Sanchez, P.D. and Juando, C. (2005) Nursing and Cancer Support Groups. Journal of Advanced Nursing, 51, 369-381. http://dx.doi.org/10.1111/j.1365-2648.2005.03508.x

[11] Fors, E.A., Bertheussen, G.F., Thune, I., Juvet, L.K., Elvsaas, I.-KØ., Oldervoll, L., et al. (2011) Psychosocial Interventions as Part of Breast Cancer Rehabilitation Programs? Results from a Systematic Review. Psycho-Oncology, 20, 909-918.

[12] Hoey, L.M., Ieropoli, S.C., White, V.M. and Jefford, M. (2008) Systematic Review of Peer-Support Programs for People with Cancer. Patient Education and Counseling, 70, 315-337. http://dx.doi.org/10.1016/j.pec.2007.11.016

[13] Morse, K.D., Gralla, R.J., Petersen, J.A. and Rosen, L.M. (2013) Preferences for Cancer Support Group Topics and Group Satisfaction among Patients and Caregivers. Journal of Psychosocial Oncology, 32, 112-123. http://dx.doi.org/10.1080/07347332.2013.856058

[14] Pistrang, N., Jay, Z., Gessler, S. and Barker, C. (2013) Telephone Peer Support for Women with Gynaecological Cancer: Benefits and Challenges for Supporters. Psycho-Oncology, 22, 886-894. http://dx.doi.org/10.1002/pon.3080

[15] Hersch, J., Juraskova, I., Price, M. and Mullan, B. (2009) Psychosocial Interventions and Quality of Life in Gynaecological Cancer Patients: A Systematic Review. Psycho-Oncology, 18, 795-810. http://dx.doi.org/10.1002/pon.1443

[16] Cox, K. and Wilson, E. (2003) Follow-Up for People with Cancer: Nurse-Led Services and Telephone Interventions. Journal of Advanced Nursing, 43, 51-61. http://dx.doi.org/10.1046/j.1365-2648.2003.02672.x

[17] Lewis, R., Neal, R.D., Williams, N.H., France, B., Wilkinson, C., Hendry, M., et al. (2009) Nurse-Led vs. Conventional Physician-Led Follow-Up for Patients with Cancer: Systematic Review. Journal of Advanced Nursing, 65, 706-723. http://dx.doi.org/10.1111/j.1365-2648.2008.04927.x

[18] Galway, K., Black, A., Cantwell, M., Cardwell, C.R., Mills, M. and Donnelly, M. (2012) Psychosocial Interventions to Improve Quality of Life and Emotional Wellbeing for Recently Diagnosed Cancer Patients. Cochrane Database of Systematic Reviews, 11, CD007064.

[19] Sekse, R.J.T., Blaaka, G., Buestad, I., Tengesdal, E., Paulsen, A. and Vika, M. (2014) Education and Counselling Group Intervention for Women Treated for Gynaecological Cancer: Does It Help? Scandinavian Journal of Caring Sciences, 28, 112-121.

[20] Antonovsky, A. (1979) Health, Stress, and Coping. Jossey-Bass, San Francisco, 255 p.

[21] Antonovsky, A. (1987) Unraveling the Mystery of Health: How People Manage Stress and Stay Well. Jossey-Bass, San Francisco, $218 \mathrm{p}$.

[22] Rogers, C.R. (1957) The Necessary and Sufficient Conditions of Therapeutic Personality Change. Journal of Consulting Psychology, 21, 95-103. http://dx.doi.org/10.1037/h0045357

[23] Rogers, C.R. (1961) On Becoming a Person: A Therapist’s View of Psychotherapy. Houghton Mifflin, Boston, 420 p.

[24] Antonovsky, A. (2005) Hälsans Mysterium. Natur och Kultur, Stockholm, 271 p.

[25] Morgan, D.L. (1997) Focus Groups as Qualitative Research. VIII, Sage Publications, Thousand Oaks, 80 p.

[26] Dahlberg, K., Dahlberg, H. and Nyström, M. (2008) Reflective Lifeworld Research. Studentlitteratur, Lund, 370 p.

[27] Kvale, S. (1996) Interviews: An Introduction to Qualitative Research Interviewing. XVII, Sage, Thousand Oaks, 326 p.

[28] Ussher, J., Kirsten, L., Butow, P. and Sandoval, M. (2006) What Do Cancer Support Groups Provide Which Other Supportive Relationships Do Not? The Experience of Peer Support Groups for People with Cancer. Social Science \& Medicine, 62, 2565-2576. http://dx.doi.org/10.1016/j.socscimed.2005.10.034

[29] Ieropoli, S.C., White, V.M., Jefford, M. and Akkerman, D. (2011) What Models of Peer Support Do People with Co- 
lorectal Cancer Prefer? European Journal of Cancer Care, 20, 455-465.

http://dx.doi.org/10.1111/j.1365-2354.2010.01218.x

[30] Gray, R.E. and Fitch, M. (2001) Cancer Self-Help Groups Are Here to Stay: Issues and Challenges for Health Professionals. Journal of Palliative Care, 17, 53-58.

[31] Bell, K., Lee, J., Foran, S., Kwong, S. and Christopherson, J. (2010) Is There an “Ideal Cancer” Support Group? Key Findings from a Qualitative Study of Three Groups. Journal of Psychosocial Oncology, 28, 432-449. http://dx.doi.org/10.1080/07347332.2010.488140

[32] Malterud, K. (2001) Qualitative Research: Standards, Challenges, and Guidelines. The Lancet, 358, 483-488. http://dx.doi.org/10.1016/S0140-6736(01)05627-6 